Rancang Bangun Smart Church Broadcasting Sebagai Upaya Penguatan Sarana Prasarana Ibadah di Masa Pandemi Covid19

by Daniel Yeri Kristiyanto

Submission date: 11-Jun-2021 11:19AM (UTC-0400)

Submission ID: 1598998484

File name: er_Jurnal_MEANS_Daniel_Yeri_Kristiyanto_Sisilia_Thya_Safitri.pdf (278.33K)

Word count: 3122

Character count: 20014 


\title{
Rancang Bangun Smart Church Broadcasting Sebagai Upaya Penguatan Sarana Prasarana Ibadah di Masa Pandemi Covid-19
}

\author{
1) Daniel Yeri Kristiyanto \\ Institut Teknologi Telkom Purwokerto, Jl. D.I Panjaitan No.128 Purwokerto, Jawa Tengah, Indonesia \\ E-Mail: daniel@ittelkom-pwt.ac.id \\ 2) Sisilia Thya Safitri \\ Institut Teknologi Telkom Purwokerto, Jl. D.I Panjaitan No.128 Purwokerto, Jawa Tengah, Indonesia
}

E-Mail: sisil@ittelkom-pwt.ac.id

\begin{abstract}
The Covid-19 outbreak in Indonesia has changed the conventional worship procedures. Health protocols by the Government of Indonesia have Changed the worship of Church congregations from face to face become interface to interface through online worship. However, problems arise when Church administrators have little knowlege about the application of computer applications to Church services. This paper will explain the design of online-based worship using a smart broadcasting design using a simple V8 live soundcard, 16 channel audio mixer, OBS Studio 26.0.2, Computers, Church music equipment, handycam and social media channels. The results of this study are in the form of designing a Church worship system by utilizing the limited budget for purchasing professional broadcast equipment, but being able to digitize analog equipment owned by the Church. Futhermore, this study resulted in an equation of the application of Smart Church Broadcasting (SCB) using Fuzzy Tsukamoto.
\end{abstract}

Keyword : Smart Church Broadcasting, Information Systems, Social Media

\section{PENDAHULUAN}

Pandemi Covid-19 di Indonesia telah mengubah tatanan masyarakat, tidak terkecuali masyarakat Gereja. Kebijakan pembatasan kegiatan masyarakat untuk mencegah wabah ini meluas memiliki konsekuensi kepada liturgi peribadatan Gerejawi. Semula tata cara ibadah dilaksanakan secara konvensional secara face to face, namun setelah Pemerintah Republik Indonesia menerapkan kebijakan protokol kesehatan, maka Konsekuensi dari kebijakan tersebut adalah tata cara ibadah cenderung berbasis interface to interface[1]. Bagaimanapun juga, permasalahan muncul tatkala manajemen Gereja hanya memiliki pengetahuan yang terbatas mengenai pengaplikasian sistem informasi berbasis komputer yang akan digunakan pada ibadah di Gerejanya. Jika terdapat kekurangan penguasaan aplikasi ibadah online, maka hasil pengolahan informasi ibadah dapat tidak sesuai dengan apa yang diharapkan oleh pihak Gereja, hal ini disebabkan kurangnya kualitas informasi broadcasting yang sampai kepada jemaat. Sebelumnya tata cara ibadah konvensional tidak menemukan kendala berarti, namun sejak pandemi Covid-19 melanda Indonesia pada bulan Maret 2020, Gereja mulai membatasi jumlah jemaat yang datang bahkan di beberapa waktu, ibadah tidak dapat dilaksanakan[2]. Lebih lanjut, hal permasalahan tersebut menyebabkan fungsi pelayanan rohani kepada jemaat Gereja menemui sejumlah kendala.

Organisasi Gereja melalui berbagai jenis pelayanan fisiknya, yakni gedung maupun tata kelola organisasinya seolah telah menjadi sebuah keharusan, pada saat pandemi Covid-19 melanda menggunakan perangkat teknologi informasi dalam berbagai kegiatannya[3]. Teknologi informasi telah hadir dan dapat dimanfaatkan untuk membantu mengakomodasi kebutuhan peribadatan maupun kegiatan Gereja lainnya. Keterbatasan jemaat untuk menghadiri kegiatan gereja yang berpotensi menimbulkan kerumunan, menyebabkan Gereja diminta untuk menyesuaikan diri dalam melayani seluruh kebutuhan jemaat, terutama menyediakan sarana dan prasarana peribadatan yang dapat dilakukan dari rumah tanpa perlu untuk datang ke Gereja dalam masa pandemi[4].

Pemanfaatan teknologi tepat guna dapat menjadikan Gereja memiliki keunggulan strategis dalam hal pelayanan kepada jemaat[5]. Selain itu Gereja memiliki kemampuan menjangkau area yang lebih luas dan lebih dinamis, namun tetap sesuai dengan visi dan misi organisasi gerejanya. Esensi yang dapat dilakukan oleh manajemen Gereja melalui pemanfaatan teknologi informasi adalah optimalisasi saluran internet yang dimanfaatkan secara optimal, sehingga memungkinkan pelayanan jemaat akibat pandemi Covid-19 tidak berhenti, namun tetap dapat diikuti melalui perangkat mobile maupun non mobile yang dimiliki oleh jemaat yang terhubung ke internet. Perangkat tersebut misalnya internet TV, Smartphone, Laptop maupun Personal Computer[6]. Pelayanan Gerejawi berbasis online juga mampu memberikan manfaat bagi Gereja yang lain untuk mencontoh memulai ibadah dengan dinamis, 
tertata, terstandart dan lebih baik dari sebelumnya. Di sisi lain, manajemen Gereja dapat menggunakan hal tersebut untuk mengatur, memantau, dan mengelola organisasinya secara lebih efektif dan efisien.

Konsep Smart Church Broadcasting (SCB) dirancang untuk dapat digunakan dengan mudah dan relative murah dan dalam penggunaannya tidak diperlukan keahlian khusus dalam bidang ilmu broadcasting maupun programming. Penggunaan SCB hanya memerlukan sumber daya manusia yang telah dilatih dan terbiasa dengan program aplikasi Smart Church Broadcasting. Secara singkat Smart Church Broadcasting adalah serangkaian pengaturan sistem informasi dari berbagai macam alat dan data multimedia yang ada di dalam sebuah organisasi Gereja yang bertujuan untuk menyimpan, melindungi, mengambil kembali dan menyebarkan informasi agar dapat digunakan kembali data multimedia tersebut. Hal ini dapat diartikan bahwa SCB merupakan sebuah strategi sekaligus metodologi. Nama Smart Church Broadcasting (SCB) adalah deskripsi yang menggambarkan isi dari nama Smart Church itu sendiri, yang berasal dari dua konsep yang saling dihubungkan, yakni Smart dan Church yang bermakna seluruh pengolahan sistem informasi Gereja akan menerapkan teknologi cerdas yang murah, mudah serta tepat guna. Senada dengan hal diatas hadirnya Smart Church akan diintegrasikan ke dalam sebuah manajemen Gereja yakni Smart Church Broadcasting yang dapat terhubung ke berbagai media official elektronik yang dimiliki Gereja seperti Facebook, Instagram, dan Youtube Channel.

Studi ini menjelaskan rancang bangun penerapan Smart Church Broadcasting pada organisasi Gereja sebagai upaya penguatan sarana ibadah di masa pandemi Covid-19. Tujuan khusus penelitian ini adalah untuk membangun dan menyediakan infrakstruktur rintisan dan unit inkubator Smart Church Broadcasting (SCB) yang sinergi dengan sistem informasi Gereja, dan diharapkan keberhasilan implementasinya, organisasi Gereja dapat menjadi dinamis dan tetap dapat memberikan pelayanan kepada jemaat di tengah pandemi Covid-19 berbasis digital elektronik yang dapat dinikmati secara live streaming maupun on demand. Lebih lanjut studi ini digunakan untuk mengukur tingkat kehadiran jemaat pada saat live streaming, dan seberapa banyak jemaat yang mengikuti siaran ibadah secara digital. Data yang masuk dapat digunakan untuk bahan pertimbangan manajemen Gereja untuk pelayanan jemaat lebih lanjut.

\section{BAHAN DAN METODE}

Penelitian ini . memiliki gagasan strategi pelaksanaan ibadah di Gereja dapat dilakukan dengan cara yang berbeda dan lebih fleksibel.
Jemaat dapat juga menyaksikan secara On Demand ibadah yang ada, melalui perangkat yang dimiliki yakni smartphone, laptop atau perangkat mobile yang lain yang memiliki akses terhadap internet. Rancangan lain sistem ibadah yang ditawarkan dapat juga melalui model campuran (Blended) dimana ibadah dapat dilakukan secara langsung dan tidak langsung dalam satu waktu. Di era pandemi Covid-19 fleksibilitas ibadah menjadi suatu kebutuhan yang penting, karena lingkungan fisik yang terkadang tidak memungkinkan dilakukan secara langsung. Strategi ibadah dalam masa pandemi Covid-19 yang dapat dilakukan secara blended secara real time, serta memberikan kesempatan jemaat untuk dapat juga menyaksikan secara on demand siaran ibadah, dikenal dengan istilah Smart Church Broadcasting. Smart Church Broadcasting tidak terbatas pada jarak atau ruang, namun telah dapat menjadi solusi ibadah di tengah masa pandemi yang belum jelas kapan berakhir.

Rancangan Smart Church Broadcasting ini diimplementasi menggunakan metode eksperimental, dimana sebelumnya belum pernah dilakukan proses digitalisasi pada objek penelitian. Metode ekperimen merupakan metode penelitian yang dapat digunakan dalam mencari pengaruh atau treatment tertentu pada satu objek[7]. Proses sebelumnya adalah ibadah sistem konvensional dengan cara jemaat datang ke gereja secara langsung. Lebih lanjut, penelitian ini dilakukan di Gereja GPdI Parakletos Purwokerto sebagai unit inkubator pelaksanaan rancang bangun dan implementasinya..Secara umum perancangan system Smart Church Broadcasting yang di usulkan adalah sebagai berikut:

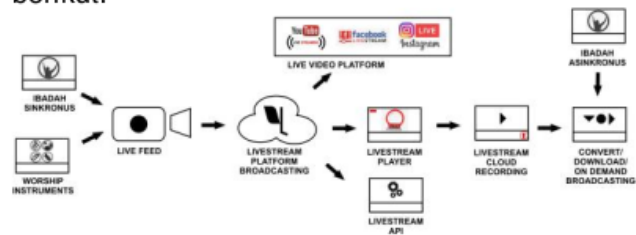

Gambar 1. Distribusi Sumber Broadcasting Jemaat Gereja pada Smart Church Broadcasting

\section{A. System Requirements}

Sistem Smart Church Broadcasting yang dibangun memerlukan alat komputer sebagai media digitalisasi sumber siaran. System requirements dalam pengembangan sistem ini dibagi ke dalam dua hal, yakni system requirements hardware dan system requirements software. Pada prinsipnya requirements yang ada dalam penelitian ini dibuat dengan sederhana dan anggaran terbatas namun mampu digunakan untuk melakukan siaran digital. Lebih lanjut system requirements yang dibangun memanfaatkan alat yang sudah tersedia di Gereja sebelumnya. Secara umum system requirements untuk hardware adalah 
standart instruments musik elektrik dan sound amplifier mono atau stereo, wire Microphone, wireless microphone atau condenser microphone dengan frequency response (FR) $100 \mathrm{~Hz}-8000 \mathrm{~Hz}$, untuk kualitas $\mathrm{Hi}$-Definition atau $\mathrm{Hi}-\mathrm{Fi}$ microphone yang digunakan memiliki $\mathrm{FR} 20 \mathrm{~Hz}$ sampai $20.000 \mathrm{~Hz}$ dengan impedance sebesar $600 \Omega$ hingga 10.000 $\Omega$ [8]. Audio Power Amplifier stereo frequensi $10 \mathrm{~Hz}-50 \mathrm{HZ}$, Binding Post $2 \times 400 \mathrm{~W} / 8 \Omega$, $2 \times 800 \mathrm{w} / 4 \Omega$, Bridge $1200 \mathrm{~W} / 8 \Omega$, untuk penggunaan audio power ini dapat menggunakan watt yang lebih rendah atau tinggi sesuai kebutuhan.

System requirements untuk audio mixer yang digunakan menggunakan frequency response $+0.5 /-1.5 \mathrm{~dB}(2 \mathrm{~Hz}-48 \mathrm{kHz})$, equivalent input noise $-128 \mathrm{dBu}(2 \mathrm{~Hz}-20 \mathrm{kHz}$, Rs: $150 \Omega$, Gain Knob:max). Kebutuhan audio mixer dapat menyesuaikan keadaan Gereja masing-masing, semakin tinggi spesifikasi semakin baik pula produksi suara yang diproduksi dan dihasilkan[9]. Visualisasi diproduksi dari laptop atau personal komputer dan disalurkan ke layar besar melalui LCD proyektor melalui Splitter HDMI 4 Port. Inputan dari proses visual berasal dari kamera utama Handycam kualitas HD 1080 pixel. Inputan dapat menggunakan kamera smartphone yang dihubungkan ke wifi lokal dan diakses ke komputer melalui aplikasi. Rekomendasi semakin tinggi pixel dan kemampuan kamera semakin baik pula produksi gambar yang dihasilkan. Ibadah yang sedang berlangsung didukung dengan tata lampu sensor suara par led $54 \times 3$ watt RGBW, AC110-220V 50/60Hz. Kebutuhan tata lampu ini bersifat opsional tergantung kepada fasilitas Gereja. Penggunaan perangkat Router WIFI menggunakan spesifikasi Port rate $10 \mathrm{Mbit} / \mathrm{s}, 100 \mathrm{Mbit} / \mathrm{s}$, or $1000 \mathrm{Mbit} / \mathrm{s}$, max transmission distance $100 \mathrm{~m}$ working mode autoadaptive $10 \mathrm{Mbit} / \mathrm{s}, 100 \mathrm{Mbit} / \mathrm{s}$ or $1000 \mathrm{Mbits} / \mathrm{s}$. WIFI Router dengan spesifikasi lebih tinggi akan menghasilkan kestabilan koneksi dan daya tampung koneksi perangkat lebih baik[10].

Kebutuhan software memanfaatkan aplikasi open source Open Broadcaster Software (OBS) versi 26.0.2, untuk kamera spekulasi atau kamera mobile memanfaatkan software Iriun Webcam. Aplikasi presentasi maupun videografi dan video player menggunakan berbagai macam vendor. Implementasi SCB akan mengandung konsekuensi bahwa organisasi akan selalu memproduksi data secara berkelanjutan[10]. Lebih lanjut, setelah system requirements untuk hardware dan software terpenuhi maka, selanjutnya adalah pengujian implementasi SCB melalui penilaian rentang waktu uji coba system. Rentang waktu yang disepakati dalam penelitian ini adalah enam bulan. Penilaiannya menggunakan metode Fuzzy Tsukamoto dengan instrument penelitian berupa kuesioner[11]. Hasil rancang bangun fisik Smart Church Broadcasting yang ekperimental tersebut, kemudian dinilai tingkat efektivitasnya menggunakan variabel adopsi Smart City menggunakan fuzzy

Tsukamoto.

\section{B. Proses Digitalisasi}

Proses digitalisasi dalam penelitian ini berprinsip kepada empat hal yakni: Capture, Encode, Go Live, serta Retrieve/Decode. Capture adalah proses mendapatkan sumber siaran berupa video dan audio yang berasal dari input hardware seperti kamera dan microphone untuk kemudian diolah menggunakan software. Peralatan musik, amplifier dan microphone disatukan menggunakan junk box melewati media kabel coaxial khusus menuju ke mixer audio utama, sinyalnya diperkuat menggunakan power amplifier untuk sound system indoor. Sedangkan untuk media siaran digital, sinyal suara didigitalisasi menuju ke sound card v8 menuju ke komputer. Proses tersebut disebut sebagai Encode, yakni proses merubah data analog menjadi data digital berbasis multimedia. Langkah selanjutnya setelah proses Encode yakni proses Go Live. Proses Go Live menyatukan semua data audio dan data visual yang berasal dari perangkat melewati audio mixer dan soundcard. Proses ini membutuhkan aplikasi tertentu untuk mengolah data multimedia tersebut untuk kemudian ditayangkan sebagai siaran ibadah online. Data yang otentik merupakan data yang utama dalam proses smart broadcasting[12].

Tools yang diperlukan adalah menggunakan Open Broadcaster Software (OBS) dan Official YouTube Channel yang sudah dibuat sebelumnya. OBS dipilih karena memiliki beberapa kemampuan diantaranya adalah: pengambilan dan penggabungan video atau audio real-time kinerja tinggi, kemampuan membuat adegan/scene yang terdiri dari berbagai sumber termasuk tangkapan layar di komputer berupa teks, jendela, gambar, kamera dan fitur lainnya. Pada saat menggunakan OBS scenes yang digunakan tidak dibatasi untuk diciptakan, sehingga memudahkan manipulasi visual, kemampuan lain adalah intuitive audio mixer with per-source filters seperti halnya noise gate, noise suppression, and gain. Take full control with VST any pluggin.OBS sangat diperlukan ketika ibadah live streaming maupun ibadah dengan recording. Kemampuan menggabungkan audio visual yang baik menjadi penting dalam proses Smart Church Broadcasting. Interface akhir dari rangkaian Smart Church Broadcasting adalah YouTube Channel. Peranannya adalah sebagai interface yang dapat dilihat oleh jemaat melalui perangkat seperti smartphone, PC, laptop atau bahkan smart TV. Siaran dari Youtube dapat pula di broadcast ke berbagai media sosial seperti Instagram, Facebook dan lain sebagainya, sehingga jemaat dapat lebih fleksibel dalam mengikuti ibadah menggunakan berbagai platform sosial media 


\section{HASIL DAN PEMBAHASAN}

A. Basis Formulasi Penilaian Implementasi SCB

Rancang bangun Smart Church Broadcasting (SCB) dalam penelitian ini berfokus kepada implementasi dan deployment sebagai solusi pelaksanaan ibadah dimasa pandemi Covid-19. Variabel pelaksanaanya berpijak kepada teori Smart City, dimana secara konseptual dibagi kedalam enam variabel yakni Governance, Economy, Mobility, People, Living dan Life. Adopsi konsep smart city kedalam SCB memiliki tujuan yakni implementasi fisik pada organisasi gereja dapat juga selanjutnya untuk dilakukan pengukuran hasil implementasi di masa yang akan datang. Rumusan pengukuran terlebih dahulu diproyeksikan ke dalam fungsi input dan fungsi output, sehingga tampak sebagai berikut:

Tabel 1. Variabel Smart Church Broadcasting

\begin{tabular}{|c|c|}
\hline Function & Variable \\
\hline \multirow{4}{*}{ Input } & Governance \\
\cline { 2 - 2 } & Economy \\
\cline { 2 - 2 } & Mobility \\
\cline { 2 - 2 } & People \\
\cline { 2 - 2 } & Living \\
\cline { 2 - 2 } & Live \\
\hline Output & Estimated Effectiveness \\
\hline
\end{tabular}

Estimasi Estimasi efektivitas rancang bangun SCB dalam penelitian ini menggunakan fuzzy logic method. Metode fuzzy yang dipilih adalah Tsukamoto. Konsep determinan domain fuzzy dibagi dalam klasifikasi dan jangkauan, yang nantinya dalam pengembangan SCB dapat dijadikan acuan pengembangan program selanjutnya. Klasifikasi dibagi kedalam tiga indikator yakni: Buruk, Netral, Baik. Range dibagi kedalam tiga hal juga yakni: $<50$ range buruk, $50<x<80$ range netral, dan $>80$ range baik. Formulasi dasar aturan Fuzzy Tsukamoto adalah sebagai berikut:

$$
Z=\frac{z_{0}^{\prime} \alpha(i) z(\hat{i})}{z_{0}^{\prime} z(\hat{i})}
$$

Dimana:

$\alpha=$ Alpha Predikat ( Nilai Minimum derajat Keanggotaan)

$\mathrm{Zi}=$ Crisp Value (Diperoleh dari Rumus Derajat Himpunan Keanggotaan Fuzzy yang Merupakan Nilai Keluaran)

$Z$ = Center Average Defuzzyfier (Rerata Defuzzyfikasi Terpusat)

\section{B. Sistem Validasi}

Metode Fuzzy dapat digunakan sebagai validator efektifitas rancang bangun Smart Church Broadcasting. Tahap pertama diawali dengan implementasi fisik eksperimental SCB untuk ibadah Gereja. Tahap ke dua adalah dengan penerapan formulasi penilaian menggunakan Tsukamoto Fuzzy Logic. Testing dan validasi dilakukan menggunakan kuesioner dalam form yang telah tervalidasi. Fom validator yang digunakan mengandung grading value dari variabel yang telah ditetapkan pada table 1 . Skor final ditentukan dari hasil tersebut digunakan untuk menilai tingkat efektivitas rancang bangun Smart Church Broadcasting, apabila nilainya kurang maka dapat dilakukan treatment berupa optimasi di bagian variabel tersebut.

System validasi didasarkan kepada enam variabel Smart Church Broadcasting yakni: Governance, Economy, Mobility, People, Living dan Live. System Classifikasi efektivitas implementasi SCB adalah sebagai berikut:

Tabel 2. Sistem Validasi Domain

\begin{tabular}{|c|c|c|c|c|c|c|}
\hline Variabel & \multicolumn{2}{|c|}{ Klasifikasi } & \multicolumn{3}{c|}{ Range } \\
\hline $\begin{array}{c}\text { Governan } \\
\text { ce }\end{array}$ & Buruk & Rerata & Baik & $<50$ & $\begin{array}{c}<50 x< \\
80\end{array}$ & $>80$ \\
\hline Economy & Buruk & Rerata & Baik & $<50$ & $\begin{array}{c}<50 x< \\
80\end{array}$ & $>80$ \\
\hline Mobility & Buruk & Rerata & Baik & $<50$ & $\begin{array}{c}<50 x< \\
80\end{array}$ & $>80$ \\
\hline People & Buruk & Rerata & Baik & $<50$ & $\begin{array}{c}<50 x< \\
80\end{array}$ & $>80$ \\
\hline Living & Buruk & Rerata & Baik & $<50$ & $\begin{array}{c}<50 x< \\
80\end{array}$ & $>80$ \\
\hline Live & Buruk & $\begin{array}{c}\text { A } \\
\text { Rerata }\end{array}$ & Baik & $<50$ & $\begin{array}{c}<50 x< \\
80\end{array}$ & $>80$ \\
\hline
\end{tabular}

Fungsi keanggotaan untuk Smart Church Broadcasting menggunakan ekuasi sebagaimana berikut ini:

$\mu$ Buruk $[\mathrm{X}]$

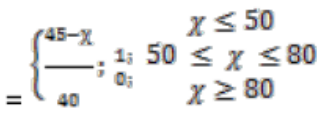

Rerata[X]

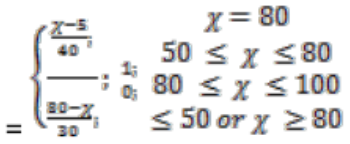

$\mu$ Baik $[X]$

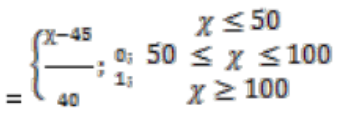

\section{Hasil Penerapan Smart Church Broadcasting}

Ibadah sinkronus merupakan pelaksanaan ibadah di Gereja secara real time, artinya konsep ini dapat dilakukan secara langsung seperti ibadah pada umumnya, namun ditambah dengan aplikasi SCB yang disiarkan secara langsung melalui official sosial media Gereja seperti Youtube, Instagram dan Facebook. Tujuannya adalah jemaat dapat secara fleksibel mengikuti ibadah, baik datang langsung ke Gereja maupun mengikuti secara online pada jam ibadah yang telah diatur oleh pihak Gereja.

Ibadah asinkronus merupakan pelaksanaan ibadah Gereja secara tidak langsung. Penerapan SCB pada ibadah Gereja 
memungkinkan gereja untuk melakukan recording ibadah dan ditayangkan sesuai jadwal yang diatur oleh gereja. Lebih lanjut, konsep ibadah asinkronus dapat disaksikan secara "On Demand", sesuai dengan keinginan jemaat tanpa memerlukan waktu khusus. Konsep asinkronus ini selain dihasilkan dari proses recording dapat juga secara otomatis diproses melalui siaran langsung melalui streaming pada media Youtube.

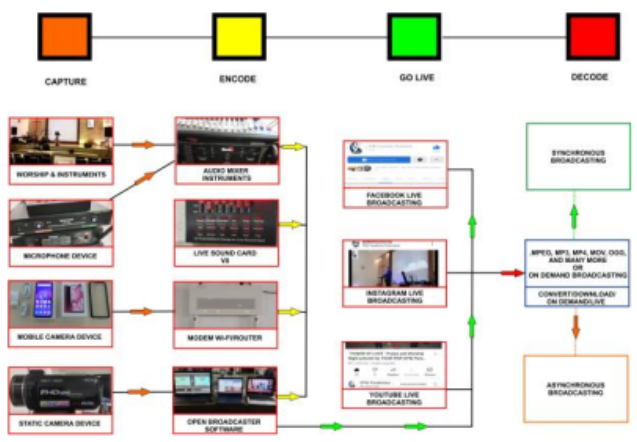

Gambar 2. Rancang Bangun Smart Church Broadcasting

Penerapan system validasi dilakukan setelah sistem berada dalam dalam mode alpha, yakni ketika sudah mencapai waktu tertentu yang disepakati yakni per enam bulan. Penerapan sistem validasi dalam penelitian ini masih dalam masa uji coba, namun formulasi variabelnya telah ditetapkan seperti pada table 2 .

\section{KESIMPULAN}

Implementasi . rancang bangun Smart Church Broadcasting (SCB) berhasil diimplementasikan pada ibadah di Gereja GPdl Parakletos Purwokerto. Aplikasi SCB mampu memberikan kontribusi signifikan terhadap pelayanan jemaat Gereja pada saat Pandemi Covid-19. Aplikasi SCB memberikan keleluasaan bagi para jemaat untuk dapat mengikuti ibadah secara Sinkronus maupun Asinkronus di tengah pembatasan sosial berskala besar yang ditetapkan oleh pemerintah Indonesia. SCB di siarkan melalui kanal media sosial yang biasa digunakan oleh masyarakat yakni Youtube, Facebook, Serta Instagram dengan tujuan melayani jemaat melalui platform digital. Lebih lanjut, Smart Church Broadcasting mampu bekerja dengan cara mendigitalisasi peralatan analog seperti alat-alat musik menjadi satu kesatuan yang dinamis. Formulasi estimasi efektivitas rancang bangun SCB berhasil di bentuk, namun untuk mengujinya masih memerlukan waktu uji yakni selama satu semester berjalan sehingga metode fuzzy Tsukamoto yang di gunakan dapat digunakan untuk mengukur variabel Smart Church Broadcastingnya. Implementasi SCB dapat diaplikasikan dengan menggunakan budget pendanaan yang relatif ringan hingga budget melimpah yang disesuaikan dengan Gereja masing-masing.

\section{UCAPAN TERIMAKASIH}

Ucapan terimakasih kepada Direktorat Jenderal Pendidikan Tinggi, Kementerian Pendidikan, Kebudayaan, Riset, dan Teknologi Republik Indonesia atas bantuan dana penelitian melalui Ucapan terimakasih kepada Direktorat Jenderal Pendidikan Tinggi, Kementerian Pendidikan, Kebudayaan, Riset, dan Teknologi Republik Indonesia atas bantuan dana penelitian melalui program Penelitian Dosen Pemula Tahun Anggaran 2021.

\section{DAFTAR PUSTAKA}

[1] A. rizky anugerah, P. suksessanno muttaqin, and D. adi Purnama, "Effect of Large-Scale Social Restriction (PSBB) during COVID-19 on Outdoor Air Quality: Evidence from Five Cities in DKI Jakarta Province, Indonesia," Environ. Res., vol. 197, no. November 2020, p. 111164 , 2021, doi: 10.1016/j.envres.2021.111164.

[2] F. Salesman and T. Mm, "Catholic Church Services in Pandemic Coronavirus Disease ( Covid-19 ) in the Diocese Ruteng - Indonesia," J. Qual. Heal. care Econ., vol. 4, no. 2, 2021, doi: 10.23880/jqhe-16000208.

[3] W. He, Z. Justin, and W. Li, "International Journal of Information Management Information technology solutions challenges, and suggestions for tackling the COVID-19 pandemic," vol. 57, no. December 2020, 2021, doi: 10.1016/j.jijnfomgt.2020.102287.

[4] Terézia Ron`cáková, "Closed Churches during the Pandemic: Liberal versus Conservative and Christian versus Atheist Argumentation in Media," Department of Journalism, Faculty of Arts and Letters, Catholic University in Ružomberok. pp. 018, 2021.

[5] N. B. Ossai-ugbah, "Ossai-Ugbah_use of ICT," Int. J. Sci. Technol. Educ. Res., vol. 2, no. March, pp. 49-57, 2011.

[6] J. Arthur and C. Rensleigh, "The use of online technologies in the small church," SA J. Inf. Manag., vol. 17, no. 1, pp. 1-6, 2015, doi: $10.4102 /$ sajim.v17i1.630.

[7] A. Shah, S. Cheng, D. E. Longman, S. S. Goldsborough, and T. Rockstroh, "An experimental study of uncertainty considerations associated with predicting auto-ignition timing using the Livengood- 
Wu integral method," Fuel, vol. 286, no. November 2020, p. 119025, 2021, doi: 10.1016/j.fuel.2020.119025.

[8] W. M. Systems, "Selection and Operation Wireless Microphone Systems." 2014.

[9] H. Davies, "Religious Devices: A Survey of Technologies of Worship.," Intersect. Media Archaeol., vol. 7, no. 2, 2019.

[10] G. E. Sadhvi and P. N. Tejus, "Automatic Detection of Stronger Wi-Fi Networks," Int. Res. J. Eng. Technol., vol. 4, no. 11, pp. 1679-1681, 2017.
[11] E. Nugraha, A. P. Wibawa, M. L. Hakim, U. Kholifah, R. H. Dini, and M. R. Irwanto, "Implementation of fuzzy tsukamoto method in decision support system of journal acceptance," J. Phys. Conf. Ser., vol. 1280 , no. 2 , 2019, doi: $10.1088 / 1742-$ $6596 / 1280 / 2 / 022031$.

[12] D. Y. Kristiyanto, B. Suhartono, and A. Wibowo, "Digital Forensic InnoDB Database Engine for Employee Performance Appraisal Application," 2019, doi: $10.1051 / e 3 s c o n f / 201$. 
Rancang Bangun Smart Church Broadcasting Sebagai Upaya Penguatan Sarana Prasarana Ibadah di Masa Pandemi Covid19

ORIGINALITY REPORT

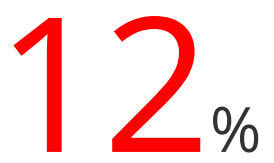

SIMILARITY INDEX

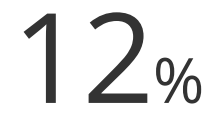

INTERNET SOURCES
$6 \%$

PUBLICATIONS
$\%$

STUDENT PAPERS

PRIMARY SOURCES

1

"Proceedings of the 1st International

Conference on Electronics, Biomedical

Engineering, and Health Informatics", Springer

Science and Business Media LLC, 2021

Publication

2 jurnal.uisu.ac.id

3 ejournal.ust.ac.id

$4 \quad$ p3m.poliban.ac.id

Internet Source

5 www.ihs.nl

Internet Source

6 www.mediatec.de Internet Source

Ashish Shah, Song Cheng, Douglas E. Longman, S. Scott Goldsborough, Toby

Rockstroh. "An experimental study of 
uncertainty considerations associated with

predicting auto-ignition timing using the

Livengood-Wu integral method", Fuel, 2021

Publication

8 list.waikato.ac.nz

Internet Source

9 daten-quadrat.de

N D Lynn, A W R Emanuel. "Strategic

Information Systems Planning for Higher

Education in Uganda", IOP Conference Series:

Materials Science and Engineering, 2021

Publication

11

es.scribd.com

Internet Source

12 hrcak.srce.hr

Internet Source

13 docplayer.net

Internet Source

14 journal.binadarma.ac.id

Internet Source

15 ro.ecu.edu.au 
18 www.kopertis7.go.id

19 afidburhanuddin.wordpress.com

20 www.academicjournals.org

21 core.ac.uk 